\title{
How the Musicality of Ethnolinguistic Affects the Cognitive Abilities for Further Learning
}

\author{
Genc Struga* \\ Department of Neuroscience, University Hospital, Albania
}

*Corresponding author: Genc Struga, Department of Neuroscience, University Hospital, Mother Teresa, Tirana, Albania.

Received Date: August 13, 2018

Published Date: August 24, 2018

\section{Short Communication}

The Albanian native speaker's have a better pronunciation or accent of the foreign language they learn and these phenomena are unique in so called Indo-European languages group, a family group where Albanian is one of the oldest surviving member. Albanian language richness in sound is expressed with writing system of different large alphabets up to 53 letters. Further certain element of ethnography of singing such as iso-polyphony considered by UNESCO as word heritage which has been a form of ancient singing in north as well in the south Albania including Macedonia still vivid in Albania. Characterized by songs consisting of two solo parts, a melody and a countermelody with a choral drone. The structure of the solo parts varies according to the different ways of performing the drone, which has a great variety of structures, especially in the popular style adopted by all groups performing this music. There are these language characteristics and ethnography that affects the native neuroplasticity abilities in learning another language easier and with better pronunciation or accent.

This process is similar to musician ability of better cognitive abilities for learning and better pronunciation.

This factor is independent of CPH (critical period hypothesis) influencing L2 (second language) acquisition better pronunciation or accent. Other than influence of CPH on L2 speech pronunciation or foreign accent is the fact whether the L1 is native language and how close is this native language to L2 language etymological formation. The Albanian abilities seems more prominent in the languages more close to theirs inside the Indo-European languages. 